\title{
Empathize and Sympathize with Less Privileged Academic Fraternity
}

\author{
Adhikarla Suryanarayana Rao \\ Department of Biotechnology, Bharathidasan University, Tiruchirappalli, India \\ Email address: \\ asraobio@gmail.com \\ To cite this article: \\ Adhikarla Suryanarayana Rao. Empathize and Sympathize with Less Privileged Academic Fraternity. Higher Education Research. \\ Vol. 5, No. 4, 2020, pp. 162-166. doi: 10.11648/j.her.20200504.17
}

Received: July 15, 2020; Accepted: August 3, 2020; Published: August 13, 2020

\begin{abstract}
Academic fraternity in different countries of the world though work honestly, face several hurdles to project themselves - a fact that needs to be realized. In this context it is definitely fair to say that it was unfortunate in the past to defame a very a large number of authors and journals and continue to nurture this attitude till today. Authors pursuing their endeavors honestly are demoralized. Personal experiences cannot be documented but are only spread by word of mouth. Both on the basis of personal experiences and available documented data, no one is so sacrosanct. Fact of enormous pressure of gargantuan expansion in higher education has to be viewed from all angles. One most important aspect of this is, authors all over the world-even with all their limitations- wish to establish an evidence of their work \& contribution and project their academic concern and caliber at the earliest. Maligning publishers and maligning authors / academic institutions is an unfortunate thing. International scientific community should adopt a friendly policy towards all. Let every candidate-at whatever level one may be-be interrogated and evaluated in person by the concerned employer for whatever may be the purpose. Hence, maligning of journals and candidates in any form may be avoided.
\end{abstract}

Keywords: Journal Controversy, Differential Relevance of Research, Gargantuan Number of Researchers, Resource Crunch, Academic Pressures, Limitation of Publishing Space

\section{Introduction and Background}

At the outset I sincerely request the understanding of all concerned target groups to view this article purely as an attempt to boost the morale of huge number of academic fraternity from different countries all over the world.

\subsection{Origin of the Journals Controversy}

Maligning publishers and maligning authors / academic institutions is an unfortunate thing. This is a consequence of numerous journals being categorized as something otherwise. In this process a huge number from academic fraternity and numerous academic institutions across the world get unduly maligned apart from the publishers/ journals [1-3]. Of course the list has been subsequently removed by the originator and hence its validity is now being debated [1-2]. A point to be noted is, this list does not cover many journals run by public institutes and official societies in different countries. And another list is made available only on subscription which all may not solicit [3]. The primary focus by the originator was only on private publishers and did not include others in spite of their heavy charges for publishing $[1,2,4]$.

\subsection{Why It Is Fair for Authors to Resort to Publish in Certain Journals}

The fact of unusual delays and financial pressure has been duly acknowledged in favor the authors even by researchers in developed west [4].

In fact huge number in many countries publish in journals run by the educational institutions and official societies within their respective countries as they do not charge anything but they may have other draw backs like unusual delay in publication and rejections for more than one reason. Hence, authors may avoid even these official native journals and resort to affordable paid journals of private publishersparticularly those on open access-. These private journals have some plus points as they too are cosmopolitan in nature, that is, the journals have papers of authors from different countries in the world and because of the shorter time taken 
for publication. Further, these journals make available free of charge articles of other authors from different countries and their papers are helpful in many ways and they do quote references from globally reputed journals in their articles. Globally reputed or approved journals do not offer articles free of charge but charge considerably for every article to view or take a print out. Academic fraternity was facing a waste of time in contacting the authors to get their articles. Fortunately, DOI system has come and more fortunately a precious philanthropic gift for millions in academic field has come up-sci-hub browser. One should note that this is widely acknowledged as a response "to the high cost of research papers behind pay walls which have been held in esteem as per [1-3]". The hub site is extensively used worldwide. As on September 2019, it has apparently served approximately 400,000 requests per day The number of articles claimed is frequently updated on the site's home page, being over 81 million in April 2020. So one can imagine the problems of millions of academic fraternity across the world because of the high business model of globally reputed and approved journals. Hence, the above browser has been lauded by in the scientific, academic, and publishing communities for providing access to knowledge generated by the scientific community free of cost [5-6]. One cannot make this hub defunct or criticize as millions of academic fraternity-at all levels of hierarchy-are immensely benefitted by this. On similar lines one should think and should not criticize authors publishing in certain journals and their publishers. They do have a genuine utility.

\subsection{Why Criticism of Authors Is Not Really Fair}

An unfortunate criticism [1-3] is that a large number of authors come from Asian and Africa countries. Whosoever passes such criticism should understand the fact that these two continents Asia and Africa constitute are the largest populated, constituting more than $70 \%$ of the global population and nearly $42 \%$ of the total countries in the world and with a larger percentage of younger population aspiring to be in higher education and come up [7-11]. Further their extent of backwardness both in science \& technology and economic status and budget allocated to Science \& Technology varies a lot [12-14]. Another point which has not been widely recognized is that even from North America and Europe and from middle and high income countries also large number of authors do contribute the same/similar journals [15-16]. This indicates the above mentioned draw backs and some other draw backs in their system. So naturally, drawbacks will be there and even more in Asian and African continents and hence it is not fair to blame the authors or publishers from these countries.

Long back erstwhile USSR, the country made almost mandatory to publish within the country and that too in native language-Russian. Similar was the situation in the mainland China. Even today many countries, Russia, China, Japan etc publish a lot in their own country and in their respective native languages. So the problem comes/or is more only if authors are to publish in English. Because of lack of journals in native languages and the desire to reach more people in developed English speaking countries authors resort to publish in English where they face stiff competition particularly with the developed English speaking countries.

The fact that journals from private publishers had been increasing over a period of time is a clear reflection of the above mentioned facts. What is the other way out for the above target groups working in the vast number of institutions in numerous countries? In future their problem is very likely going to be intensified as there is still a lot of societal pressure to expand higher education and research in so many places across the world.

It is an utter disappointment to authors and so they have no other go than to try to avoid this chagrin by accordingly choosing journals where they can make the work known to others and establish an evidence of their work and contribution at the earliest. This aspect-establishing an evidence of their work and contribution at the earliest-is of primary concern to the authors. Hence, neither they should be maligned nor the journals in which they have published should be maligned.

\subsection{Coining the Term "Predatory" Is Not Really Fair}

It is unfortunate that a harsh term "Predatory" has been coined [1-2]. Because of this, it is fair to ask, Who are the "Preys"!? Authors? At least authors do not feel so-by and large-as so many globally reputed journals are run on a highly business model-by and large. These globally reputed journals may charge far more-5-10 times or even more-and in spite of that, they may take four times more time to publish [4]. Their annual revenues can be much more [17-19]. The above factors can be great hindrances for many authors from underdeveloped and developing-in particularly highly populated and/or economically poor-and others facing financial crunch and time pressure for any reason whatsoever.

Access to full articles In this digital era for maintaining open access any publisher has to incur some expenditure. This money cannot be counted under "predation".

Another problem is that of manuscript rejection has become too common. A study by Hall and Wilcox concluded that $62 \%$ of the published papers have been rejected at least once. Rejection rates for journals can be as high as $87 \%$. Reasons can be more than what have been already mentioned [20-23]. There can be many genuine limitations more particularly for authors from developing/ low and even middle income countries to contribute to widely approved world reputed journals.

Any fellow academician in the concerned subject can definitely understand the contents of the paper even if there are shortcomings in the manner in which it is written. In fact many academicians conduct $\mathrm{PhD}$ Viva Voce examination for a thesis written in a different language and the student presenting in a different language even in the developed world. Similarly, many audience in the conferences listen and understand the importance of the work of authors / speakers hailing from different countries whose English speaking skills are poor. Here it is apt to mention that in the present er, 
spell check, spacing mistakes and grammatical errors can be checked on the computer itself by the author (s) before sending for publication. Even for this some globally reputed journals ask the authors to approach a service agent who can do the above to their satisfaction. Service agent fees is in addition to the cost of publication of the articles as mentioned above. And the fact is even with the same amount which these agents charge or even less, authors from many countries can cover their whole publishing cost of their articles in certain journals! So naturally authors are disposed in this way and no need to blame either the author (s) or the journal (s)/publishers.

Another point to be widely recognized is, there are significant number of retractions of papers even from globally reputed journals and of authors of developed countries. Every year the number of retractions had been increasing and crossed 700 and as per 2020 there are 21,792 items. Number of authors including co-authors are estimated to be nearly 30,000 . So where the reviewing has gone wrong?? Apparently, even globally reputed journals with all their advantages cannot claim of $100 \%$ good peer reviewing [24-31].

\section{Analysis of Gargantuan Expansion in Higher Education}

It has been mentioned above because of huge population and eligible group for higher education etc, there had been and there is still a lot of societal pressure to expand higher education and research in so many places across the world.

There is a gargantuan increase in number of educational institutions and academic personnel at all levels of hierarchy. Though there also had been increase in the number of journals they fall too short-for the gargantuan expansion of higher education and research in 193 countries plus territories [32-33] across the world.. Of the above, only a few countries are often discussed for various parameters like number of PhD's produced, papers published etc leaving behind a vast number of countries. Many organizations rank the universities in the world. THE (Times Higher Education) 2019 ranked 1,250 universities. QS ranked 18,640 universities. After ranking in series up to 200, it resorted to ranking in a class interval i.e 201-250; 251-300...801-1000 and finally 1001 plus. In this $1001+$ category also there are many universities from different continents. According to Quora information on a site there are 28,000 universities in the world as of 2019. Webometrics ranks 30,000 institutions. Even the above number does not really cover all the institutions/ categories of institutions across the world. Any serious discussion is centered around top 100 or 200 or so or on OECD countries which are around 35 and most of them are located in Europe and America. India is often discussed along with the OECD etc in view of the large population and large number of educational institutions. While discussing, black African countries are almost ruled out and so with many Asian countries etc. [34-38]
How many of the Master's, PhD's, Post-Docs, Faculty from the above can publish in widely approved high quality journals? Is it possible to get their paper through in widely approved high quality journals-either paid or unpaid? For such huge number it is not possible to publish even in low quality journals which are otherwise approved. Some problems have been mentioned above Viz; financial crunch, problems of rejections and undue delays in publication, low amount of money allocated to science budget and another important factor is the nature of work which can be of provincial relevance. What is the other way out for the above target groups working in the vast number of institutions in numerous countries? The gargantuan expansion of $\mathrm{PhD}$ students (all $\mathrm{PhD}$ students have a research supervisor) in different countries over a period of time has been discussed at length from different angles in the reputed "Nature" journal and others both in terms of absolute numbers and percentages and serious concern was expressed. However, only very few countries have been covered [39-46]. Publication problems have been exacerbated because of publication being made mandatory even for Master's students and they also have a pressure to publish in the interest of their future career prospects. Even in just one country-India-the number of Master's students have been estimated to be nearly four million and in US sixteen million. Other countries vary in between or fall short of and everyone is aspiring to have a higher enrollment in higher education [47-50]. In future their problem-PhD and master's students and faculty-is very likely going to be intensified as there is still a lot of societal pressure to expand higher education and research in so many places across the world.

\section{Authors \& Publishers Need to Be Vindicated Even in Future}

It is clear from the above mentioned that there is an inevitable need and variety of pressures for numerous people to publish with as much ease as possible. Hence, there is no point in maligning the authors and thereby academic institutions for publishing in certain journals. People resort to different journals in varying numbers depending on their permissible disposition. Authors from different countries have to ever look for other options There can be privileged few who have no problem in getting their papers published anywhere. But the vast majority have to struggle. Hence, the need for friendly policies to deal with the mammoth task. Just imagine the world population of 7.8 billion as on now and projected to increase further. Even if we put a low figure of $1 \%$ of the total population to have doctorate, how much it comes to!? If one aspires a greater percentage, $2 \%, 3 \%$ etc the task is more herculean. In addition to $\mathrm{PhD}$, enrollment in Masters degree also adds to millions who are also expected to publish. Is it possible for the existing journals to accommodate the wide variety of papers of all these millions? Alternatively, there should be a total reframing of policies in Education and Science \& Technology. A friendly policy is, 
malice and prejudice towards none. Rather the policy should be morale boosting. Let no body be maligned just for what one is apparently. Let every candidate-at whatever level one may be-be interrogated and evaluated in person by the concerned employer for whatever may be the purpose. Hence, maligning of journals and candidates in any form may be avoided.

\section{Conclusion}

Because of many genuine prameters/limitations Viz; huge population in countries in the continents like Asia and Africa etc; dire need for increase in GER (gross enrollment ratio) in higher education and thereby resulting in gargantuan expansion in higher education; need to work on relevant research areas of provincial relevance; need to provide students at different levels some teaching material; financial crunch and other problems in publishing -as mentioned in the text - a vast number of academicians resorting to various journals convenient to them is very much justified. Hence, it is unfair to belittle them in any way.

\section{Acknowledgements}

My sincere thanks to Dr. Anil Kumar Moola and $\mathrm{Mr}$ Prabhas for sparing the laptop. I am highly thankful to $\mathrm{Mr}$. Raja who has been delivering essentials to my home during this corona crisis. Thanks are also due to Dr. S. Sivaramakrishnan, Head Department of Biotechnology and Dr. S. Sridhar for day to day help.

\section{References}

[1] https://en.wikipedia.org/wiki/Predatory_publishing.

[2] https://beallslist.net/.

[3] https://en.wikipedia.org/wiki/Cabell\%27s_blacklist.

[4] Cathy Vakil (2019) Predatory journals-Authors and readers beware. Canadian Family Physicians, 65: 92-94. PMC 6515480 .

[5] sci-hub.tw.

[6] Sci-Hub-https://en.wikipedia.org/wiki/Sci-Hub.

[7] Countries in Asiahttps://www.worldometers.info/geography/how-manycountries-in-asia/.

[8] https://www.worldatlas.com/webimage/countrys/as.htm.

[9] Asia-https://en.wikipedia.org/wiki/Asia.

[10] Countries in Africahttps://www.worldometers.info/geography/how-manycountries-in-africa/.

[11] List of African countries by populationhttps://en.wikipedia.org/wiki/List_of_African_countries_by_p opulation.
[12] How much does your country invest in $R$ \& $D$ ? http://uis.unesco.org/apps/visualisations/research-anddevelopment-spending/.

[13] GDP per capita-https://www.worldometers.info/gdp/gdp-percapita/.

[14] GDP by country-https://www.worldometers.info/gdp/gdp-bycountry/.

[15] Shen, C. and Björk, B. C. (2015) Predatory' open access: a longitudinal study of article volumes and market characteristics. BMC Med. 13: 230. doi: 10.1186/s12916-0150469-2.

[16] Moher D. et al (2017) Stop this waste of people, animals and money. Nature, 549: 23-25. doi:/10.1038/549023a.

[17] https://en.wikipedia.org/wiki/Springer_Nature.

[18] https://en.wikipedia.org/wiki/Taylor_\%26_Francis.

[19] https://en.wikipedia.org/wiki/Elsevier.

[20] Ish Kumar Dhammi and Rehan-Ul-Haq (2018) Rejection of Manuscripts: Problems and Solutions. Indian J Orthop. 52: 9799. doi:/10.4103/ortho.IJOrtha_68_18.

[21] Hall, S. A. and Wilcox, A. J. (2007). The fate of epidemiologic manuscripts: A study of papers submitted to epidemiology. Epidemiology. 18: 10.1097/01.ede.0000254668.63378.32. 262-265.

[22] Wager, E. Getting Research Published. Oxon, UK: Radcliffe Publishing Ltd; 2005.

[23] https://www.enago.com/academy/learning-to-avoid-journalrejection/.

[24] https://www.enago.com/academy/database-of-retractedpapers-launched-for-researchers/ (November 13, 2018).

[25] Retractions rise to nearly 700 in fiscal year 2015https://retractionwatch.com/2016/03/24/retractions-rise-tonearly-700-in-fiscal-year-2015-and-psst this-is-our-3000thpost/.

[26] https://en.wikipedia.org/wiki/Retraction_Watch.

[27] The Retraction Watch Database-retractiondatabase.org. Retrieved 2019-08-06.

[28] https://en.wikipedia.org/wiki/Retractions_in_academic_publis hing.

[29] Jeffrey Brainard (2018) Rethinking retractions. Science, 362: 390-393. doi: 10.1126/science.362.6413.390.

[30] Alison Maccok (2018) One publisher, more than 700 retractions. Science, 362: 393. doi: 10.1126/science.362.6413.394.

[31] Alison Maccok (2018) Fallout for co-authors. Science, 362: 394-395. doi: 10.1126/science.362.6413.394-b.

[32] Countries in the worldhttps://www.worldometers.info/geography/how-manycountries-are-there-in-the-world/.

[33] How many countries are there 2020?-https://worldpopulationreview.com/country-rankings/howmany-countries-are-there. 
[34] World University Rankings 2019 | Times Higher Education (THE) www.timeshighereducation.com > 2019.

[35] https://www.timeshighereducation.com/world-universityrankings/2019/world-ranking.

[36] https://www.topuniversities.com/university-rankings/worlduniversity-rankings/2021.

[37] https://www.quora.com/How-many-universities-are-there-inthe-world-4.

[38] http://www.webometrics.info/en.

[39] David Cyranoski, Natasha Gilbert, Heidi Ledford, Anjali Nayar and Mohammed Yahia (2011). The PhD factory. 472: Nature, 276-279. doi: /10.1038/472276a.

[40] Taylor, M. (2011). Reform the PhD system or close it down. Nature 472: 261. doi: /10.1038/4722761a.

[41] Fiske, P. (2011). What is a PhD really worth?. Nature 472: 381. doi: /10.1038/472280a.

[42] Alison McCook (2011) Education: Rethinking PhDs. Nature 472: $280-282$.
[43] Editorial-Fix the PhD (2011). Nature 472: 259-260. doi: $/ 10.1038 / 472259 b$.

[44] Anjali Nayar (2011). Developing world: educating India. Nature, 472: 24-26. doi: /10.1038/472024a.

[45] https://academia.stackexchange.com/questions/47563/what-istotal-number-of-phds-globally-how-many-graduate-each-year.

[46] https://www.quora.com/How-many-PhD-holders-are-there-inthe-world.

[47] https://mhrd.gov.in/sites/upload_files/mhrd/files/statisticsnew/AISHE2015-16.pdf.

[48] Bharath Kancharla (2019)-October 22 Factlyhttps://factly.in/gross-enrolment-ratio-ger-of higher-educationimproves-but-challenges-remain $\% \mathrm{EF} \% \mathrm{BB} \% \mathrm{BF} /$.

[49] Max Roser and Esteban Ortiz-Ospina (2013) Tertiary Education-https://ourworldindata.org/tertiary-education.

[50] https://en.wikipedia.org/wiki/List_of_countries_by_tertiary_e ducation_attainment. 